УДК 631.41:631.453

\title{
АККУМУЛЯЦИЯ ТЯЖЕЛЫХ МЕТАЛЛОВ В ПОЧВАХ СВЕРДЛОВСКОЙ ОБЛАСТИ
}

\author{
Харина Галина Валерьяновна ${ }^{1}$, \\ gvkharina32@yandex.ru
}

\author{
Алешина Людмила Викторовна², \\ alv@usue.ru \\ 1 Российский государственный профессионально-педагогический университет, \\ Россия, 620012, г. Екатеринбург, ул. Машиностроителей, 11. \\ 2 Уральский государственный экономический университет, \\ Россия, 620144, г. Екатеринбург, ул. 8-е Марта, 62.
}

\begin{abstract}
Актуальность исследования продиктована необходимостью проведения постоянного экологического мониторинга объектов окружающей среды в Свердловской области, в частности, почв в связи с высоким уровнем антропогенной нагрузки на территории.

Цель работы заключается в оценке степени загрязнения селитебных ландшафтов и сельскохозяйственных угодий в Свердловской области тяжелыми металлами путем определения концентрации валовых форм тяжелых металлов и вычисления количественных критериев загрязнения тяжелыми металлами.

Объекты: пробы почв из нескольких пунктов Свердловской области, представляющих урбанизированные территории и сельскохозяйственные угодья.

Методы: механическая и химическая пробоподготовка почв; потенциометрический метод для определения характера среды почв; метод инверсионной вольтамперометрии для определения концентрации валовых форм тяжелых металлов.

Результаты. Установлено соответствие точек отбора проб почвенным провинциям, приведена краткая характеристика гранулометрического и геохимического состава исследуемых почв. Обнаружено, что анализируемые почвы загрязнены никелем, цинком, свинцом и медью; имеет место многократное превышение ориентировочно-допустимых концентраций никеля в почвах Екатеринбурга и Первоуральска. Перечислены основные источники техногенного загрязнения почв Свердловской области тяжелыми металлами. Рассмотрены природные факторы, способствующие аккумуляции металлов; описаны возможные механизмы закрепления тяжелых металлов в почвах области. Проведено ранжирование металлов-загрязнителей по их содержанию в исследуемых почвах. Рассчитаны количественные критерии степени загрязнения почв: суммарный показатель загрязнения и индекс геоаккмуляции. На основании полученных значений указанных параметров показано, что почвы селитебных ландшафтов характеризуются умеренно опасным уровнем загрязнения, почвы сельскохозяйственного назначения допустимым уровнем загрязнения. Установлено, что наибольший вклад в суммарный показатель загрязнения вносит кадмий.
\end{abstract}

\section{Ключевые слова:}

Тяжелье металлы, техногенное загрязнение, селитебный ландшафот, аккумуляция, геохимический состав.

\section{Введение}

Почва выполняет важнейшие функции в биосфере, среди которых и поддержание постоянного химического состава всех геологических оболочек, и обеспечение взаимодействия геологического и биотического круговоротов, и накопление необходимых для плодородия органических веществ, и т. д. Однако именно почва является едва ли не самой уязвимой геосферой с точки зрения техногенного воздействия. Наиболее сильные негативные изменения в результате интенсивной хозяйственной деятельности испытывают почвы промышленных регионов, к которым относится Свердловская область, расположенная в пределах Среднего и Северного Урала и на равнинах Западной Сибири. Большие площади хвойных лесов, относительно плодородные почвы (особенно на юго-востоке области), богатые месторождения полезных ископаемых обусловливают развитие различных видов промышленности, включающих горнодобывающие, металлургические, машиностроительные, химические и другие предприятия [1]. В этой связи Свердловская область отличается чрезвычайно высоким уровнем загрязнения атмосферного воздуха, воды и почв. Значительный ущерб окружающей природной среде наносят предприятия горнодобывающей промышленности, черной и цветной металлургии, топливноэнергетического комплекса, в результате деятельности которых фактически полностью уничтожается плодородный слой земли за счет аккумуляции токсичных веществ, в том числе тяжелых металлов. Не случайно некоторые города Свердловской области (Ревда, Кировград) по степени загрязнения почв отнесены к группе с чрезвычайно опасной экологической ситуацией [2]. Полиэлементные геохимические аномалии, формирующиеся в результате техногенного воздействия промышленных предприятий на окружающую среду, вызывают загрязнение подземных и поверхностных вод [3], оказывают негативное влияние на различные биохимические процессы в почвах. Повышенное содержание тяжелых металлов в окружающей среде способствует развитию патологий практически всех систем организма человека: репродуктивной, пищеварительной, выделительной и т. д. [4-6]. Более того, избыточные концентрации тяжелых металлов в почвах являются фактором развития эндемических заболеваний. В этой связи экологический мониторинг почв с учетом региональных природных и техногенных геохимических особенностей, позволяю- 
щий выявить приоритетные металлы-загрязнители и определить уровень санитарно-гигиенического неблагополучия урбанизированных территорий, становится особенно актуальным.

Учитывая вышеизложенное, цель данной работы заключалась в оценке степени загрязнения селитебных ландшафтов и сельскохозяйственных угодий в Свердловской области тяжелыми металлами. Для достижения поставленной цели решались следующие задачи: определение концентрации валовых форм тяжелых металлов в точках отбора проб; определение количественных критериев загрязнения тяжелыми металлами; изучение зависимости загрязнения тяжелыми металлами от структуры ландшафта; установление источников загрязнения.

\section{Методы и материаль}

Для анализа были отобраны пробы почв из нескольких пунктов Свердловской области, представленных в табл. 1. Пробы были отобраны согласно требованиям ГОСТа 17.4.3.01-83 «Охрана природы. Почвы. Общие требования к отбору проб» с глубины 0-10 и 30-40 см [7].

Пробы почв были высушены в сушильном шкафу при температуре $40{ }^{\circ} \mathrm{C}$, измельчены в агатовой ступке до порошкообразного состояния и просеяны через сито с диаметром отверстий 1 мм. Для получения водных вытяжек навески образцов почв массой 25 г были залиты дистиллированной водой объемом 250 мл, выдержаны в течение суток и отфильтрованы; для получения кислых вытяжек навески образцов почв массой 5 г были залиты раствором азотной кислоты (1:1) объемом 100 мл, выдержаны в течение суток и отфильтрованы.

Таблица 1. Точки отбора проб почв

Table 1. Soil sampling sites

\begin{tabular}{|c|c|}
\hline $\begin{array}{l}\text { № пробы } \\
\text { Sample } \\
\text { number }\end{array}$ & $\begin{array}{l}\text { Место отбора пробы } \\
\text { Sampling place }\end{array}$ \\
\hline 1 & $\begin{array}{l}\text { Екатеринбург, Кировский р-н, центр } \\
\text { Ekaterinburg, Kirovsky district, center }\end{array}$ \\
\hline 2 & $\begin{array}{l}\text { Екатеринбург, Кировский р-н, мкр-н Комсомольский } \\
\text { Ekaterinburg, Kirovsky district, } \\
\text { Komsomolsky microdistrict }\end{array}$ \\
\hline 3 & $\begin{array}{l}\text { Екатеринбург, Орджоникидзевский р-н, } \\
\text { мкр-н Уралмаш } \\
\text { Ekaterinburg, Ordzhonikidzevsky district, } \\
\text { Uralmash microdistrict }\end{array}$ \\
\hline 4 & $\begin{array}{l}\text { Екатеринбург, Орджоникидзевский р-н, } \\
\text { мкр-н Эльмаш } \\
\text { Ekaterinburg, Ordzhonikidzevsky district, } \\
\text { Elmash microdistrict }\end{array}$ \\
\hline 5 & $\begin{array}{l}\text { Екатеринбург, Ленинский р-н } \\
\text { Ekaterinburg, Leninsky district }\end{array}$ \\
\hline 6 & $\begin{array}{l}\text { CHT «Восток», в } 30 \text { км к югу от Екатеринбурга } \\
\text { SNT «Vostok», } 30 \mathrm{~km} \text { south of Ekaterinburg }\end{array}$ \\
\hline 7 & $\begin{array}{l}\text { Коллективный сад в } 66 \text { км к юго-западу } \\
\text { от Екатеринбурга } \\
\text { Collective garden, } 66 \mathrm{~km} \text { southwest of Ekaterinburg }\end{array}$ \\
\hline 8 & $\begin{array}{l}\text { д. Мурзинка, в } 30 \text { км к северу от Екатеринбурга } \\
\text { Murzinka village, } 30 \mathrm{~km} \text { north of Ekaterinburg }\end{array}$ \\
\hline 9 & $\begin{array}{l}\text { Коллективный сад в } 14 \text { км к западу от Екатеринбурга } \\
\text { Collective garden, } 14 \text { km west of Ekaterinburg }\end{array}$ \\
\hline 10 & $\begin{array}{l}\text { Первоуральск, p-н трубного завода } \\
\text { Pervouralsk, the area of pipe plant }\end{array}$ \\
\hline
\end{tabular}

В водных вытяжках почв были определены значения $\mathrm{pH}$ потенциометрическим методом с использованием стеклянного электрода. Кислые вытяжки почв были проанализированы на содержание в них тяжелых металлов: меди, свинца, кадмия, цинка, никеля методом инверсионной вольтамперометрии (ИВА) с использованием анализатора инверсионного вольтамперометрического по ТУ 4215-001-05828695-95 (НПВП «ИВА», г. Екатеринбург).

Измерения массовой концентрации ионов меди, свинца, кадмия, цинка основаны на концентрировании определяемого металла в виде амальгамы на поверхности рабочего электрода в результате предварительного электролиза анализируемого раствора при потенциале предельного диффузионного тока с последующей регистрацией величины максимального анодного тока электрорастворения осадка [8]. Величина аналитического сигнала, регистрируемого при электрорастворении осажденного металла, прямо пропорционально зависит от концентрации ионов определяемого металла.

Измерения массовой концентрации никеля основаны на адсорбционном концентрировании на поверхности электрода комплексного соединения никеля (II) с диметилглиоксимом. Максимальный катодный ток восстановления комплексного соединения, локализованного на поверхности рабочего электрода, прямо пропорционально зависит от содержания ионов Ni (II) в растворе. Расчет массовой концентрации элементов в растворе производят с помощью метода стандартной добавки.

\section{Результаты исследований и их обсуждение}

На рис. 1 указаны точки отбора проб почв, которые входят в состав как селитебных ландшафтов, так и сельскохозяйственных угодий, то есть места отбора проб дифференцированы по степени антропогенной нагрузки на окружающую среду: либо на урбанизированных территориях с действующими промышленными предприятиями, либо неподалеку от автомагистралей. Из табл. 1 следует, что пункты отбора проб находись как в промышленных, так и в рекреационных зонах.

Согласно карте почвенно-географического районирования [9] места отбора проб почв соответствуют четырем почвенным районам (П - Полевской, Т - Таватуйский, Б - Березовский, С - Сысертский). Полевской и Таватуйский почвенные районы входят в состав Среднеуральской южнотаежной, а Березовский и Сысертский - в состав Зауральской южнотаежной почвенных провинций. В составе почвенного покрова Среднеуральской южнотаежной провинции доминируют автоморфные и полугидроморфные горные дерново-подзолистые почвы (более 50 \%), хотя встречаются и горные дерново-подзолистые, и горные лесные бурые, и горные примитивные почвы. В гранулометрическом составе большинства указанных почв присутствуют частицы крупной пыли, ила и суглинистые фракции. Специфика химического состава почв данной провинции заключается в преобладании магния над кальцием и железа над алюминием за счет особенностей почвообразующих горных пород [9]. Все почвы характеризуются невысоким содержанием фосфора и кислой реакцией среды. 


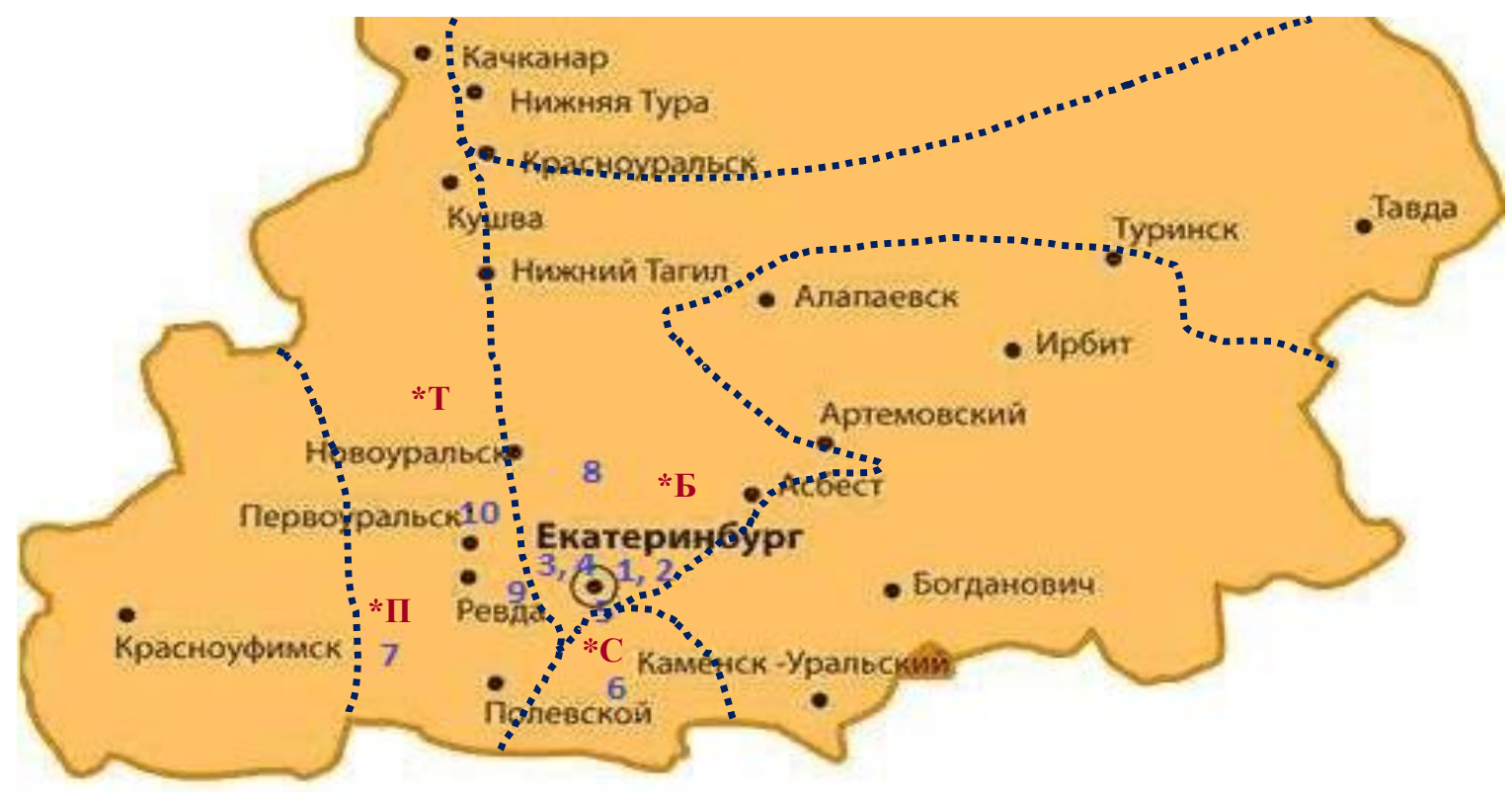

Pис. 1. Карта южной части Свердловской области с местами отбора проб почв. П, Т, Б, С-почвенные районы, соответствующие местам отбора проб; пунктиром обозначены примерные границы почвенных районов

Fig. 1. Map of the southern part of the Sverdlovsk region with soil sampling sites. $\Pi, T, E, C$ - soil areas corresponding to sampling sites; the dotted line indicates the approximate boundaries of soil areas

Почвенный покров Зауральской южнотаежной почвенной провинции представлен горными лесными бурыми и горными дерново-подзолистыми почвами с преобладанием почв равнинного облика - дерновоподзолистых. Химический состав характеризуется постоянством содержания диоксида кремния $\mathrm{SiO}_{2}$, низким содержанием фосфора и преобладанием фульфокислот над гуминовыми в составе гумуса. По морфологическому строению, гранулометрическому и химическому составу почвы данной провинции близки к почвам Среднеуральской южнотаежной провинции; характер среды почв кислый. Дополнительное закисление таких почв в результате, например, выпадения кислотных осадков или попадания сточных вод с кислой реакцией среды приводит, вопервых, к гибели полезных почвенных микрооорганизмов (например, азотфиксирующих бактерий), вовторых, к растворению соединений алюминия и марганца, представляющих опасность для растений и всех других живых организмов. Кроме того, при высвобождении связанных форм алюминия происходит его взаимодействие с соединениями фосфора с образованием труднорстворимых фосфатов.

Потенциометрическое определение характера среды водных растворов почв позволило выявить их слабокислую реакцию с рН от 5,6 до 6,8 (табл. 2).

Для определения тяжелых металлов нами был выбран метод инверсионной вольтамперометрии благодаря таким его характеристикам, как высокая точность, воспроизводимость, низкий предел обнаружения.

На рис. 2, 3 представлены примеры анодных вольтамперограмм свинца, кадмия, цинка и никеля, обнаруженных в пробах № 1, 6, 7. Как видно из рис. 2, введение аликвоты пробы в раствор фонового электролита (ВА 1) приводит к росту аналитического сиг- нала при потенциале $(-0,4) \pm(0,1)$ В (ВА 2). В присутствии добавки стандартного раствора ионов свинца отмечается дальнейший прирост аналитического сигнала (BА 3), что позволяет определить концентрацию ионов свинца.

Аналитический сигнал меди (BА 2, рис. 3) регистрируется при потенциале $(-0,2) \pm(0,1)$ В и растет при введении добавки стандартного раствора соли меди (ВА 3).

Результаты определения характера среды и концентрации тяжелых металлов в пробах почв исследуемых металлов приведены в табл. 2.

Таблица 2. Значения рН и валовое содержание тяжелых металлов в исследуемых пробах почв

Table 2. $\quad p H$ values and the total content of heavy metals in the studied soil samples

\begin{tabular}{|c|c|c|c|c|c|c|}
\hline $\begin{array}{c}\text { Номер } \\
\text { пробы }\end{array}$ & \multirow{2}{*}{$\begin{array}{c}\text { Sample } \\
\text { number }\end{array}$} & \multicolumn{5}{|c|}{$\begin{array}{c}\text { Содержание валовых форм } \\
\text { тяжелых металлов, мг/кг }\end{array}$} \\
\hline & & \multicolumn{5}{|c|}{ Content of gross forms of heavy metals, $\mathrm{mg} / \mathrm{kg}$} \\
\hline & 5,8 & 21,5 & $\mathbf{1 6 7 , 4}$ & 21,8 & 24,3 & 0,9 \\
\hline 2 & 6,8 & 34,5 & $\mathbf{2 6 9 , 4}$ & 26,2 & 21,6 & 0,9 \\
\hline 3 & 6,1 & 82,3 & $\mathbf{1 0 3 , 0}$ & 134,0 & $\mathbf{1 6 7 , 0}$ & 1,2 \\
\hline 4 & 6,4 & 85,0 & 39,0 & $\mathbf{4 5 8 , 0}$ & 106,0 & 0,8 \\
\hline 5 & 6,7 & 55,2 & $\mathbf{2 6 8 , 0}$ & 211,0 & 122,0 & 1,0 \\
\hline 6 & 6,6 & 15,6 & 28,4 & 54,6 & 16,1 & 0,5 \\
\hline 7 & 6,0 & $\mathbf{1 8 2 , 3}$ & 6,0 & 4,8 & 4,7 & 0,3 \\
\hline 8 & 6,8 & 10,8 & 10,0 & 10,2 & 7,7 & 0,8 \\
\hline 9 & 6,5 & $\mathbf{1 7 9 , 8}$ & 57,2 & 123,0 & 64,1 & 0,7 \\
\hline 10 & 5,9 & 98,8 & $\mathbf{1 1 2 , 3}$ & $\mathbf{3 8 2 , 6}$ & $\mathbf{1 5 8 , 7}$ & 1,3 \\
\hline
\end{tabular}

Жирным выделены концентрации тяжелых металлов, превышаюшие их допустимые значения (ОДК).

The concentrations of heavy metals exceeding their permissible values (APC) are highlighted in bold.

Одним из критериев оценки загрязнения почв тяжелыми металлами являются ориентировочно допу- 
стимые концентрации (ОДК) [10], значения которых находятся в прямой зависимости от характера среды почв и их гранулометрического состава. Поскольку исследуемые почвы, согласно полученным результатам, характеризуются слабокислой реакцией среды, близкой к нейтральной, нами были взяты соответствующие значения ОДК тяжелых металлов (табл. 3) с учетом преобладающих суглинистых и глинистых фракций в структуре почв.

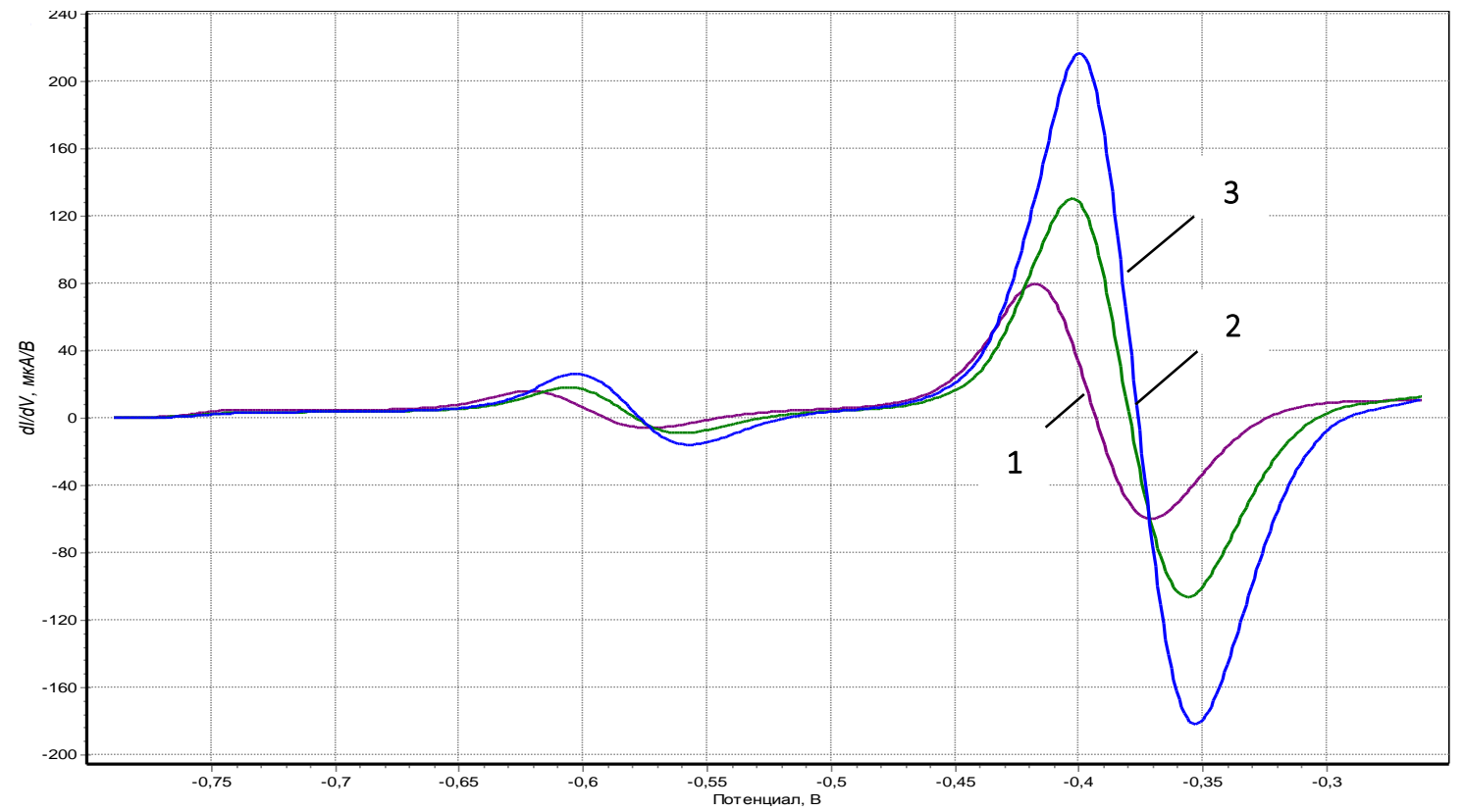

Pис. 2. Дифференциальные анодные вольтамперограммы свиниа: 1 - фон (HCl 0,1 моль/дм $), 2$ - исследуемая проба

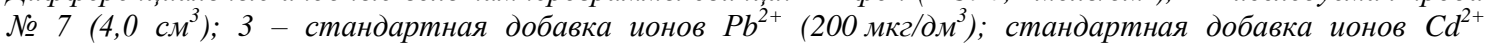
$\left(20\right.$ мкг/ $\left.\partial \mathrm{M}^{3}\right)$

Fig. 2. Differential anode voltammograms of lead: 1 - background $\left(\mathrm{HCl} 0,1 \mathrm{~mol} / \mathrm{dm}^{3}\right), 2$ - test sample no. $7\left(4,0 \mathrm{~cm}^{3}\right) ; 3-$ standard addition of $\mathrm{Pb}^{2+}$ ions $\left(200 \mathrm{mcg} / \mathrm{dm}^{3}\right)$; standard addition of $\mathrm{Cd}^{2+}$ ions $\left(20 \mathrm{mcg} / \mathrm{dm}^{3}\right)$

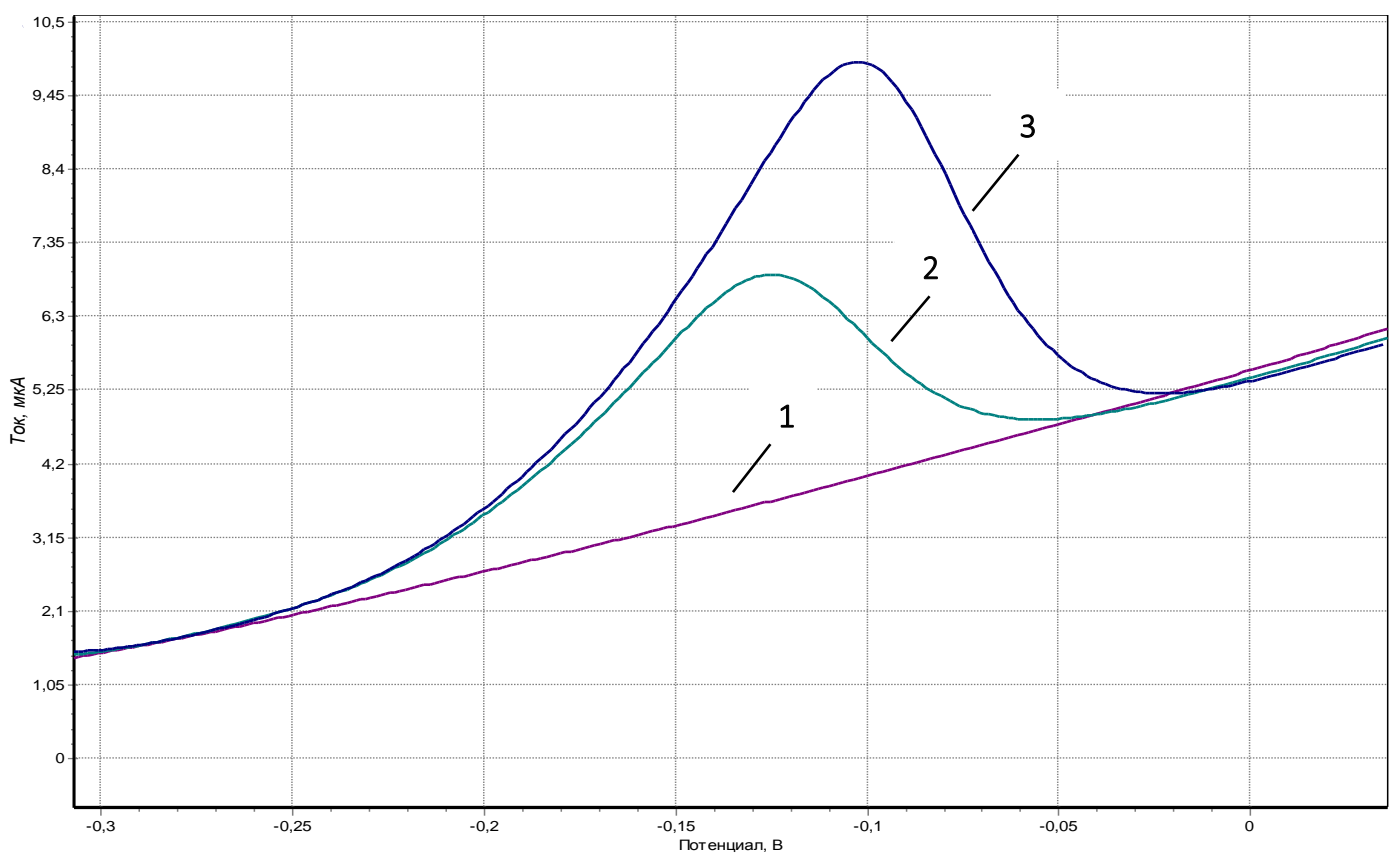

Рис. 3. Интегральные анодные вольтамперограммы меди: 1 - фон (HCl 0,1 моль/дм³), 2 - исследуемая проба № 6 $\left(2,0 \mathrm{~cm}^{3}\right) ; 3$ - стандартная добавка ионов $\mathrm{Cu}^{2+}\left(200\right.$ мкг/дм $\left.{ }^{3}\right)$

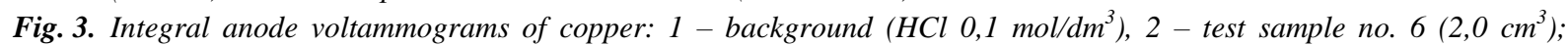
3 - standard addition of $\mathrm{Cu}^{2+}$ ions $\left(200 \mathrm{mcg} / \mathrm{dm}^{3}\right)$ 
Таблица 3. ОДК тяжельх металлов в почвах и классы их опасности

Table 3. Approximate permissible concentrations (APC) of heavy metals in soils and their hazard classes

\begin{tabular}{|c|c|c|c|c|}
\hline 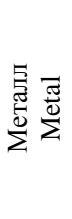 & 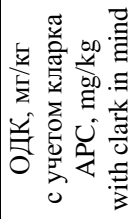 & 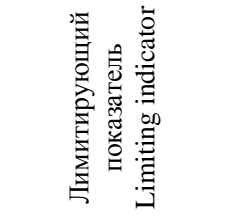 & 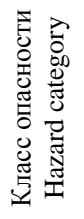 & 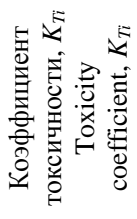 \\
\hline $\mathrm{Pb}$ & 130 & \multirow{5}{*}{$\begin{array}{l}\text { Общесанитарный } \\
\text { General sanitary }\end{array}$} & 1 & 1,5 \\
\hline $\mathrm{Ni}$ & 80 & & 2 & 1 \\
\hline $\mathrm{Zn}$ & 220 & & 1 & 1,5 \\
\hline $\mathrm{Cu}$ & 132 & & 2 & 1 \\
\hline $\mathrm{Cd}$ & 2,0 & & 1 & 1,5 \\
\hline
\end{tabular}

Как следует из табл. 2, 3, анализируемые почвы в большей степени загрязнены никелем, цинком, свинцом и медью, которые, согласно классификации опасности [11], относятся к высокоопасным (свинец, цинк) и умеренно опасным (медь, никель). Обнаружено многократное превышение ОДК никеля в почвах Екатеринбурга и Первоуральска; найдены большие концентрации свинца в почвах сельскохозяйственного назначения (почвы № 7 и 9).

При антропогенном поступлении тяжелых металлов в селитебные и промышленные ландшафты значимыми являются следующие факторы: загрязнение атмосферного воздуха продуктами сгорания топлива; геохимические особенности и загрязнение грунтовых вод; непосредственное попадание в почвы соединений тяжелых металлов при работе предприятий горнодобывающей, металлургической, машиностроительной промышленности [12]. В крупных населенных пунктах с функционирующими промышленными предприятиями и высокой концентрацией автотранспорта доля атмотехногенного загрязнения почв особенно велика. Например, в работе [13] отмечается тесная корреляция содержания тяжелых металлов в атмосферном воздухе и поверхностном слое почвы. В результате поступления антропогенных загрязнителей из различных источников в почвах урбанизированных территорий формируются техногенные геохимические аномалии с очень неравномерным распределением в них элементов.

Содержание любых элементов, в том числе тяжелых металлов, в почве определяется их концентрацией в материнских породах, структурой и химическим составом почв, характером почвообразующих процессов, значением $\mathrm{pH}$ и уровнем техногенного загрязнения [14]. Для почв Свердловской области характерно сложное геологическое строение и наличие участков с высокой природной концентрацией тяжелых металлов. К таким участкам относятся ультраосновные подстилающие горные породы, обусловливающие аккумуляцию ряда тяжелых металлов: медь, никель, хром, цинк [15].

Накопление тяжелых металлов в почве происходит также вследствие их включения в состав глинистых минералов и поглощенных оснований, взаимодействия с гумусовыми веществами с образованием прочных комплексов [16]. В результате образования труднорастворимых соединений, комплексов или физической адсорбции твердой фазой происходит закрепление тяжелых металлов в почвах. Особенно значимыми являются процессы адсорбции тяжелых металлов частицами оксидов и гидроксидов железа [17] в почве.

Свинец характеризуется высокой способностью накапливаться в почве (как в гумусовых, так и в иллювиальных горизонтах) даже в кислых средах вследствие низкой подвижности его ионов. В почвах с $\mathrm{pH}$, близким к 7, свинец образует труднорастворимые соединения, главным образом фосфаты и прочные комплексы с гуминовыми кислотами. Следствием такого связывания является устранение негативного влияния свинца на биоту почвенных экосистем. Техногенное поступление свинца в почву обусловлено главным образом работой автотранспорта, предприятий цветной металлургии, мусоросжигательных установок [18]. Авторами [19] отмечено, что при поступлении свинца от автотранспорта загрязняется полоса земли шириной 50-100 м и концентрируется в слое толщиной до 10 см. Не случайно самые высокие концентрации свинца обнаруживаются в почвах вблизи автомагистралей; последнее подтверждается результатами наших исследований: пункты отбора проб № 7 и 9 находятся вблизи оживленной автотрассы, с которой выхлопные газы, содержащие соединения свинца, оседают на поверхности земли, адсорбируются и поглощаются почвенными минералами. Почвенный покров Сысертского почвенного района, к которому относятся пробы № 7 и 9, представлен суглинистоглинистыми фракциями, на которых возможно закрепление минеральных и органических соединений свинца. Кроме того, в составе почв района обнаружено до $30 \%$ оксида железа $\mathrm{Fe}_{2} \mathrm{O}_{3}$, способного избирательно адсорбировать комплексные соединения свинца. Учитывая слабокислую реакцию среды проб № 7 и $9(\mathrm{pH}=6-6,5)$, можно предположить, что свинец в этих почвах присутствует именно в сорбированной форме.

Никель в большей степени аккумулируется ультраосновными горными породами, гранулометрический состав которых представлен тяжелыми глинами и суглинками [20]. Высокие концентрации никеля в верхнем слое почвы обусловлены техногенным загрязнением в результате сжигания органического топлива (нефти, бензина) и работы предприятий металлобрабатывающей промышленности и цветной металлургии [21]. Нами были обнаружены высокие концентрации никеля в пробах почв № 1-3, 5, 10, точки отбора которых находятся неподалеку от таких предприятий, как Уральский литейно-металлургический завод (№ 3), завод железо-бетонных изделий (№ 1, 2), Свердловский инструментальный завод (№ 5), Первоуральский трубный завод (№ 10). В почвах Зауральской южнотаежной почвенной провинции (пробы № 1-6, 8) содержание оксида железа значительно меньше, чем в Среднеуральской, - до 4,5 \%, однако, учитывая близость химических свойств железа и никеля, а также глинистые и суглинистые фракции в составе этих почв, можно предположить адсорбционный механизм аккумуляции никеля. 
Цинк в почвах присутствует в виде труднорастворимых сульфидов и фосфатов, а также комплексных соединений с серосодержащими органическими соединениями гумуса [22]. Накопление цинка, склонного к образованию легкоподвижных форм особенно в нейтральных почвах, происходит в глинистых и суглинистых отложениях. Аккумуляции цинка в виде сорбированных соединений способствуют суглинистые отложения и оксиды (гидроксиды) железа в составе почв [23-25]. Основными источниками техногенного загрязнения почв цинком являются цветная металлургия и горнодобывающая промышленность. Найденная в пробе № 4 концентрация цинка выше допустимой в два раза, что обусловлено близостью Екатеринбургской ТЭЦ и Уральского дизельмоторного завода; большое содержание цинка в пробе № 10 связано с работой многочисленных промышленных предприятий в Первоуральске.

Наибольшее количество меди (как правило, в малоподвижной форме) накапливается в основных и ультраосновных породах. Подвижность форм меди в почвах зависит не только от химического состава материнских пород, но и от уровня рН (в кислых средах подвижность возрастает), и от концентрации органических веществ в почве [26, 27]. Главными источниками техногенного загрязнения почв медью являются предприятия цветной металлургии и осадки канализационных сточных вод. Кроме того, поступление и накопление меди в селитебных ландшафтах (равно как и цинка) происходит из атмосферного воздуха при сжигании топлива, непосредственно - в результате истирания шин, тормозных колодок и легированных поверхностей.

Кадмий, близкий по своим свойствам к цинку, также накапливается в глинистых и суглинистых отложениях в виде сульфидов, карбонатов, фосфатов, однако в отличие от цинка обладает большей подвижностью, особенно в кислых средах [28]. Основу растворимого, т. е. подвижного, кадмия в почвенных растворах составляют его органические соединения [29]. Подвижные формы любых тяжелых металлов являются наиболее реакционно способными и представляют большую опасность для живых организмов. В исследуемых почвах содержание кадмия не превышает допустимых норм.

Данные табл. 2 свидетельствуют о загрязнении исследуемых почв тяжелыми металлами (кроме проб № 6, 8); превышение допустимых концентраций указанных экотоксикантов варьируется в диапазоне $1,2-3,4$ (рис. 4).

Проба почвы № 10 загрязнена тремя металлами медью, никелем и цинком, проба почвы № 3 загрязнена никелем и медью; в остальных пробах обнаружено превышение допустимого содержания только одного из определяемых металлов. Среди загрязнителей доминирует никель, повышенное содержание которого обнаружено в почвах селитебных ландшафтов. По степени загрязнения исследуемых почв определяемые металлы-загрязнители можно расположить в ряд: $\mathrm{Ni}>\mathrm{Zn}>\mathrm{Pb}>\mathrm{Cu}>\mathrm{Cd}$. Содержание кадмия во всех пробах не превышало его ОДК.

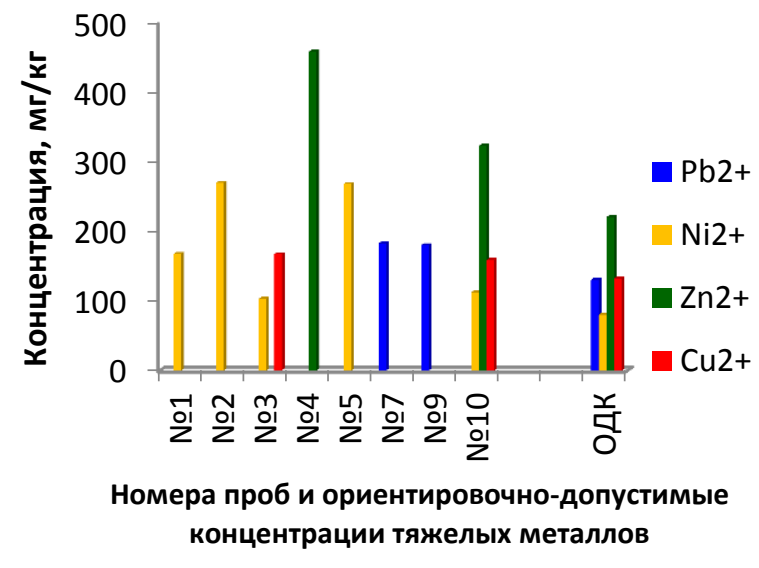

Pис. 4. Превышение ориентировочно-допустимых концентраций тяжелых металлов в пробах исследуемых почв

Fig. 4. Excess of the approximate permissible concentrations of heavy metals in the samples of the studied soils

Для оценки уровня загрязнения почв токсичными элементами, степени их вовлечения в процессы техногенеза, а также с целью определения техногенной трансформации природных ландшафтов пользуются кларками - средним содержанием элемента в верхней части земной коры. Поскольку на сегодняшний день расхождения в оценках среднего содержания одного и того же элемента в земной коре довольно велики, нами были приняты рекомендации [2], согласно которым в качестве эталонов сравнения целесообразно использовать кларки, полученные разными исследователями.

Таблица 4. Кларки тяжельх металлов в земной коре и их фоновое содержание в почвах

Table 4. Clarks of heavy metals in the Earth's crust and their background content in soils

\begin{tabular}{|c|c|c|c|}
\hline 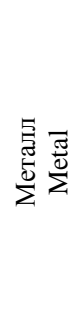 & 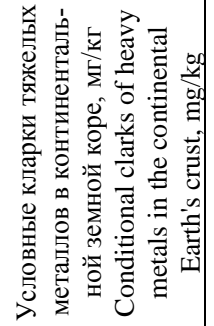 & 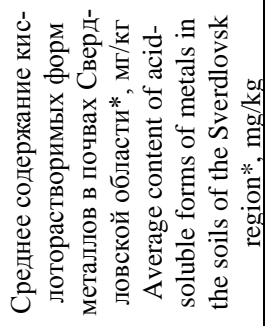 & 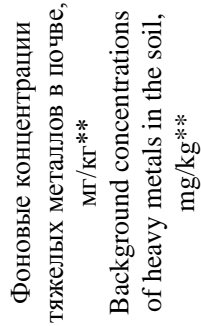 \\
\hline $\mathrm{Pb}^{2+}$ & 17 & 29 & 10 \\
\hline $\mathrm{Ni}^{2+}$ & 50 & 35 & 30 \\
\hline $\mathrm{Zn}^{2+}$ & 75 & 84 & 50 \\
\hline $\mathrm{Cu}^{2+}$ & 27 & 68 & 20 \\
\hline $\mathrm{Cd}^{2+}$ & 0,09 & 1,1 & 0,1 \\
\hline
\end{tabular}

* Среднее содержание тяжельх металлов в почвах Свердловской области приведено с учетом данных [30] за 2008г.; **фоновые концентрации ТМ в гумусовых горизонтах почв приведены по [5].

* The average content of heavy metals in the soils of the Sverdlovsk region is given taking into account the data [30] for 2008; **background concentrations of TM in humus horizons of soils are given according to [5]. 
Как следует из табл. 4, среднее содержание кислоторастворимых форм тяжелых металлов Свердловской области, за исключением никеля, превышает их условные кларки в земной коре.

Степень загрязнения почв можно оценить с помощью таких величин, как коэффициент концентрации химического вещества $K_{C i}$ и суммарный показатель загрязнения $Z_{C}[31]$ :

$$
K_{C i}=\frac{C_{i}}{C_{\phi i}},
$$

где $C_{i}$ - фактическое содержание металла в почве; $C_{\phi i}-$ фоновое содержание металла;

$$
Z_{C}=\left(\sum_{i=1}^{n} K_{C i}\right)-(n-1),
$$

где $n$ - число определяемых металлов; $K_{C i}-$ коэффициент концентрации $i$-го металла.

Однако расчет показателя $Z_{C}$ без учета степени токсичности металла не позволяет получить корректные значения. В этой связи нами была внесена поправка на токсичность в расчетную формулу $Z_{C}$ coгласно [32]:

$$
Z_{C T}=\left(\sum_{i=1}^{n} K_{C i} \cdot K_{T i}\right)-(n-1),
$$

где $K_{T i}$ - коэффициент токсичности $i$-го металла.

Согласно [31] при значениях $Z_{C}$ менее 16 загрязнение почв считается допустимым; умеренно опасное загрязнение соответствует диапазону значений 16-32; $Z_{C}$ выше 32 свидетельствует об опасном уровне загрязнения. Из табл. 5 следует, что учет коэффициента токсичности способствует увеличению суммарного показателя загрязнения: допустимым уровнем загрязнения характеризуются почвы сельскохозяйственного назначения - № 6, 8; почвы № 1-5, 7, 9 соответствуют умеренно опасной категории загрязнения, почва № 10 опасной категории. Степень загрязнения почв селитебных ландшафтов (№ 1-5, 10) закономерно выше.

Наибольший вклад в суммарный показатель загрязнения, как следует из табл. 5, вносит кадмий, поскольку его фоновое содержание в почвах Свердлов- ской области очень невелико. Результаты, представленные на рис. 5, свидетельствуют о большей степени загрязнения почвы № 10 из Первоуральска (индекс загрязнения составляет 42,5), что хорошо согласуется с данными [2, 33].

Таблица 5. Коэффициенты концентрации металлов $и$ суммарные показатели загрязнения участков местности

\begin{tabular}{|c|c|c|c|c|c|c|c|}
\hline \multirow[t]{2}{*}{ 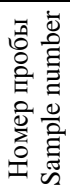 } & \multicolumn{5}{|c|}{$\begin{array}{l}\text { Коэффициенты концентрации } \\
\text { металла, } K_{C i} \\
\text { Metal concentration coefficients, } \\
K_{C i}\end{array}$} & \multicolumn{2}{|c|}{$\begin{array}{c}\text { Суммарный показатель } \\
\text { загрязнения участка } \\
\text { местности } \\
\text { Total indicator of pollution } \\
\text { of the site area }\end{array}$} \\
\hline & $\mathrm{Pb}^{2+}$ & $\mathrm{Ni}^{2+}$ & $\mathrm{Zn}^{2+}$ & $\mathrm{Cu}^{2+}$ & $\mathrm{Cd}^{2+}$ & $Z_{C}$ & $Z_{C T}$ \\
\hline 1 & 1,3 & 3,3 & 0,3 & 0,9 & 10 & 11,8 & 17,6 \\
\hline 2 & 2 & 5,4 & 0,3 & 0,8 & 10,2 & 14,7 & 25 \\
\hline 3 & 4,8 & 2,1 & 1,8 & 6,2 & 13,3 & 24,2 & 34,2 \\
\hline 4 & 5 & 0,8 & 6,1 & 3,9 & 9,1 & 20,9 & 31 \\
\hline 5 & 3,2 & 5,4 & 2,8 & 4,5 & 11 & 22,9 & 31,4 \\
\hline 6 & 0,9 & 0,6 & 0,7 & 0,6 & 5,2 & 3,9 & 7,4 \\
\hline 7 & 10,7 & 0,1 & 0,06 & 0,2 & 3,6 & 10,7 & 17,8 \\
\hline 8 & 0,6 & 0,2 & 0,1 & 0,3 & 8,3 & 5,5 & 10 \\
\hline 9 & 10,6 & 1,1 & 1,6 & 2,4 & 8 & 19,7 & 29,6 \\
\hline 10 & 5,8 & 2,2 & 5,1 & 5,9 & 17,7 & 29,7 & 42,5 \\
\hline
\end{tabular}

Table 5. Metal concentration coefficients and total indicators of contamination of terrain areas

Для более точной оценки загрязнения почв были также рассчитаны индексы геоаккумуляции тяжелых металлов [34]:

$$
I_{\text {geo }}=\log _{2} \cdot \frac{C_{n}}{1,5 B_{n}}
$$

где $C_{n}$ - концентрация элемента в верхнем слое почвы; $B_{n}-$ фоновая концентрация элемента; 1,5 - коэффициент, позволяющий компенсировать содержание элемента в фоне за счет литогенных факторов.

Существует следующая классификация загрязнения ландшафта по индексу геоаккумуляции элементов [35]: $I_{\text {geo }} \leq 0$ - практически незагрязненный; $0<I_{\text {geo }}<1$ незагрязненный до умеренно загрязненного; $1<I_{\text {geo }}<2-$ умеренно загрязненный; $2<I_{\text {geo }}<3-$ средне загрязненный; $3<I_{\text {geo }}<4$ - сильно загрязненный; $4<I_{\text {geo }}<5$ - сильно загрязненный до чрезмерно загрязненного; $5<I_{g e o}-$ чрезмерно загрязненный.

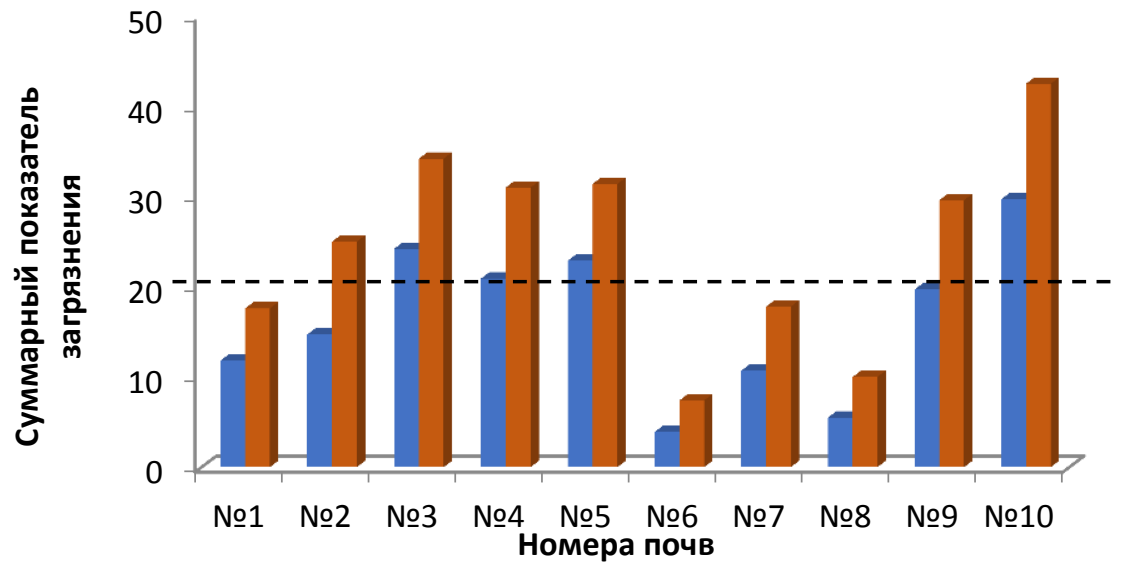

Рис. 5. Распределение исследуемых почв по суммарному показателю загрязнения

Fig. 5. Distribution of the studied soils by the total pollution indicator
Zc

ZcT

Нижняя граница умеренно опасного загрязнения 


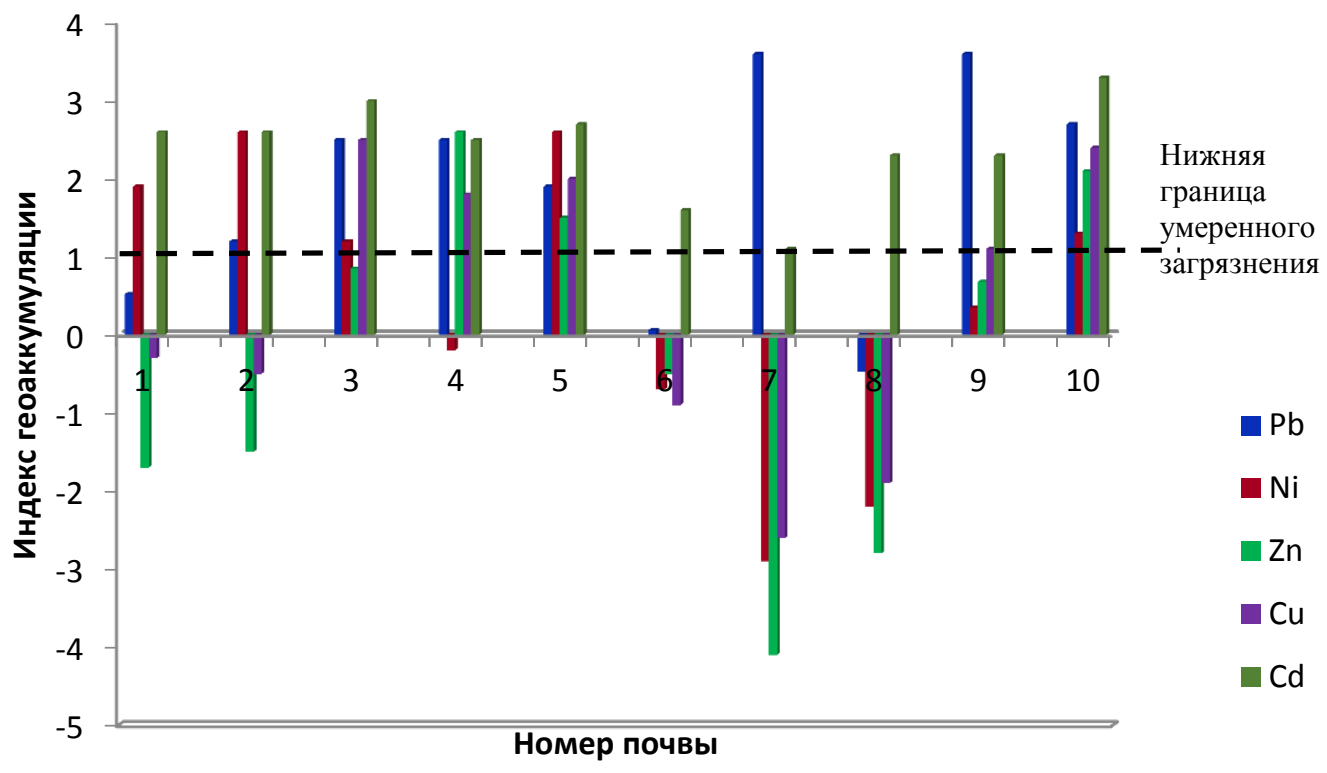

Pис. 6. Распределение почв по индексу геоаккмуляции тяжельх металлов

Fig. 6. Distribution of soils according to the index of geo accumulation of heavy metals

Как видно из рис. 6, почвы № 6-8 практически не загрязнены цинком, никелем и медью - индексы геоаккумуляции имеют отрицательные значения, это почвы сельскохозяйственных угодий, в которых содержание указанных металлов находится на уровне фонового. Почвы № 1-5, 10 (урбоземы) характеризуются средним индексом геоаккумуляции никеля, свинца и кадмия, что соответствует среднему загрязнению. Сильное загрязнение свинцом характерно для почв № 7, 9, для которых $I_{g e o}$ выше 3.

\section{Заключение}

На основании проведенных геохимических исследований обнаружено, что почвы Свердловской области характеризуются слабокислой реакцией среды и загрязнены такими тяжелыми металлами, как никель, цинк, свинец, медь. Среди загрязнителей доминирует никель, повышенное содержание которого обнаружено в почвах городских ландшафтов. Распределение металлов-загрязнителей в исследуемых почвах можно расположить в ряд: $\mathrm{Ni}>\mathrm{Zn}>\mathrm{Pb}>\mathrm{Cu}>\mathrm{Cd}$.

Выявлено, что аккумуляции указанных тяжелых металлов в почвах способствуют глинистые и сугли-

\section{СПИСОК ЛИТЕРАТУРЫ}

1. Состояние и перспективы использования минеральносырьевой базы Свердловской области на 15.03.2021. Справка подготовлена ФГБУ «ВСЕГЕИ» в рамках выполнения Государственного задания Федерального агентства по недропользованию от 14.01.2021 г. № 049-00016-21-00. URL: https://rosnedra.gov.ru/data/Fast/Files/202104/8cb09d4c5ef96b69d e56b70811dd1d5a.pdf (дата обращения 30.07.2021).

2. Касимов Н.С., Власов Д.В. Тяжелые металлы и металлоиды в почвах российских городов (по данным ежегодных докладов Росгидромета) // Вестник Московского университета. Серия 5. География. - 2018. - № 3. - С. 14-22.

3. Мониторинг качества питьевой воды в Свердловской области России / Г.В. Харина, Л.В. Алешина, С.В. Анахов, О.В. Инжеватова // Вода и экология: проблемы и решения. - 2020. № 1 (83). - C. $63-83$. нистые фракции, а также оксиды железа в составе изучаемых почв.

На основании рассчитанных значений суммарного показателя загрязнения $Z_{C T}$ установлено, что почвы селитебных ландшафтов (№ 1-5, 10) характеризуются умеренно опасной категорией загрязнения, почвы сельскохозяйственного назначения (№ 6, 8) - допустимым уровнем загрязнения. Наибольший вклад в суммарный показатель загрязнения вносит кадмий в связи с его небольшим фоновым содержанием в почвах Свердловской области. Загрязнению почв в Свердловской области способствуют такие источники техногенных эмиссий, как автотранспорт, предприятия цветной металлургии и металлообрабатывающей промышленности, теплоэлектростанции.

Индексы геоаккумуляции $I_{g e o}$ подтверждают сформулированные выше утверждения: городские почвы загрязнены тяжелыми металлами в большей степени. Почвы сельскохозяйственных угодий (№ 6-8), характеризующиеся отрицательными значениями $I_{g e o}$, практически не загрязнены тяжелыми металлами.

4. Potentially toxic elements status and distribution in Usangu agroecosystem-Tanzania / M. Mng'ong'o, S. Comber, L.K. Munishi, P.A. Ndakidemi, W. Blake, T.H. Hutchinson // Environmental Challenges. - 2021. URL: https://doi.org/ 10.1016/j.envc.2021.100200 (дата обращения 30.07.2021).

5. Михеева Е.В., Байтимирова Е.А., Голдыпева Е.В. Химическая безопасность населения: природный компонент // Технологии гражданской безопасности. - 2009. - Т. 6. - № 3-4. - С. 137-143.

6. A review of soil heavy metal pollution from mines in China: pollution and health risk assessment / Z. Li, Z. Ma, T.J. van der Kuijp, Z. Yuan, L. Huang // Science of the Total Environment 2014. - V. 468-469. - P. 843-853.

7. ГОСТ 17.4.3.01-83. Охрана природы. Почвы. Общие требования к отбору почв. - М.: Стандартинформ, 2008. - 4 c. URL: https://docs.cntd.ru/document/1200012800 (дата обращения 30.07.2021). 
8. Брайнина Х.З., Нейман Е.Я. Твердофазные реакции в электроаналитической химии. - М.: Химия,1982. -264 c.

9. Гафуров Ф.Г. Почвы Свердловской области. - Екатеринбург: Изд-во Урал. Ун-та. 2008. - $396 \mathrm{c}$.

10. Ориентировочно допустимые концентрации (ОДК) тяжёлых металлов и мышьяка в почвах: ГН 2.1.7.020-94 (Дополнение № 1 к перечню ПДК и ОДК №6229-91) Утв. ГКСН РФ. 27.12.94. - М., 1995. $-7 \mathrm{c}$.

11. ГОСТ 17.4.1.02-83. Охрана природы. Почвы. Классификация химических веществ для контроля загрязнения. - М.: Госстандарт, 1983. $-3 \mathrm{c}$.

12. Current and future emissions of selected heavy metals to the atmosphere from anthropogenic sources in Europe / E.G. Pacyna, J.M. Pacyna, J. Fudala et al. // Atmospheric Environment. 2007. - V. 41. - № 38. - P. 8557-8566.

13. Шабанов М.В., Маричев М.С. Тяжелые металлы в почвах геохимически сопряженных ландшафтов Красноуральского промышленного узла // Социально-экологические технологии. 2020. - T. 10. - № 2. - C. 201-225.

14. Physiological, biochemical changes, and phytotoxicity remediation in agricultural plant species cultivated in soils contaminated with copper and zinc / P.A.A. Ferreira, C. Lourenzi, T. Tiecher, T.L. Tiecher, F. Ricachenevsky, G. Brunetto, A.J. Giachini, C.R.F. Sauso Suares // Plants Under Metal and Metalloid Stress / Eds. M. Hasanuzzaman, K. Nahar, M. Fujita. - Singapore: Springer, 2018. - P. 29-76. URL: https://doi.org/10.1007/978-98113-2242-62 (дата обращения 30.07.2021).

15. Оценка загрязнения рекреационных зон мегаполиса тяжелыми металлами (на примере Екатеринбурга) / Е.А. Байтимирова, Е.В. Михеева, Е.Н. Беспамятных, И.М. Донник, А.С. Кривоногова // Аграрный вестник Урала. - 2016. - № 4. - С. 71-77.

16. Heike B.B. Adsorption of heavy metal ions on soils and soils constituents // Journal of Colloid and Interface Science. - 2004. V. 277. - Iss. 1. - P. 1-18

17. Васильев А.А., Чащин Н.Н. Тяжелые металлы в почвах города Чусового: оценка и диагностика загрязнения. Монография. Пермь: ФГБОУ ВПО Пермская ГСХА, 2011. - 197 с.

18. Brian J.A. Sources of heavy metals and metalloids in soils // Heavy Metals in Soils. - 2012. - V. 22. - P. 11-50.

19. Ильин В.Б. Тяжелые металлы в системе почва-растение. Новосибирск: Наука, Сиб. отделение, 1991. - 151 с

20. The link between clay mineral weathering and the stabilization of Ni surface precipitates / R.G. Ford, A.C. Scheinost, K.G. Scheckel, D.L. Sparks // Environmental Science Technology. - 1999. V. 33. - P. 3140-3144.

21. Лукин С.В. Мониторинг содержания никеля в почвах // Достижения науки и техники АПК. - 2011. - № 3. - С. 14-16.

22. Martinez C.E., Bazilevskaya K.A., Lanzirotti A. Zinc coordination to multiple ligand atoms in organic-rich surface soils // Environmental Science Technology. - 2006. - V. 40. - P. 5688-5695.
23. Zinc and arsenic immobilization and magnetite formation upon maghemite reduction by shewanella putrefaciens ATCC $8071 /$ A.C. Cismasu, G. Ona-Nguema, D. Bonnin, N. Menguy, G. Brown // Geochimica et Cosmochimica Acta. - 2008. - V. 72 (12). P. A165.

24. Zinc immobilization and magnetite formation via ferric oxide reduction by Shewanella putrefaciens / D.C. Cooper, F. Picardal, J. Rivera, C. Talbot // Environmental Science Technology. 2000. - V. 34. - P. 100-106.

25. Ford R.G., Sparks D.L. The nature of $\mathrm{Zn}$ precipitates formed in the presence of pirophyllite // Environmental Science Technology. 2000. - V. 34. - P. 2479-2483.

26. McBride M.B., Sauve S., Hendershot W. Solubility control Cu, Zn, $\mathrm{Cd}$ and $\mathrm{Pb}$ in contaminated soils // European Journal Soil Science. - 1997. - V. 48. - P. 337-346.

27. Xia K., Bleam W., Helmke P.A. Studies of the nature of $\mathrm{Cu}^{2+}$ and $\mathrm{Pb}^{2+}$ binding sites in soil humic substances using $\mathrm{X}$-ray absorption spectroscopy // Geochimica Cosmochimica Acta. - 1997. V. 61. - P. 2211-2221

28. Kubier A., Wilkin R.T., Pichler T. Cadmium in soils and groundwater: a review // Applied Geochemistry. - 2019. V. 108. - P. 104388

29. Krishnamurti G.S.R. Naidu R. Solid-solution equilibria of cadmium in soils // Geoderma. - 2003. - V. 113 (1-2). - P. 17-30.

30. Обзор фонового состояния окружающей природной среды на территории стран СНГ за 2008 год / под ред. Ю.А. Израэля // Росгидромет, 2010. - 103 c. URL: http://downloads.igce.ru/ publications/reviews/fon2008.pdf (дата обращения 30.07.2021).

31. МУ 2.1.7.730-99. Гигиеническая оценка качества почвы населенных мест. Методические указания. - М.: Федеральный центр Госсанэпиднадзора Минздрава России, 1999. - 38 с.

32. Водяницкий Ю.Н. Тяжелые металлы и металлоиды в почвах. М.: ГНУ Почвенный институт им. В.В. Докучаева РАСХН, 2008. $-84 \mathrm{c}$

33. Загрязнение почв Российской Федерации токсикантами промышленного происхождения в 2019 году. Ежегодник. - Обнинск: ФГБУ «НПО «Тайфун», 2020. -129 с.

34. Шабанов М.В., Стрекулев Г.Б. Геохимические процессы накопления тяжелых металлов в ландшафтах Южного Урала // Известия Томского политехнического университета. Инжиниринг георесурсов. - 2021. - Т. 332. - № 1. - С. 184-192.

35. Charzyński P., Plak A., Hanaka A. Influence of the soil sealing on the geoaccumulation index of heavy metals and various pollution factors // Environmental Science and Pollution Research. - 2017. V. 24. - P. 4801-4811.

Поступила 09.02.2022.

\section{Информация об авторах}

Харина Г.В., кандидат химических наук, доцент кафедры математических и естественнонаучных дисциплин Российского государственного профессионально-педагогического университета.

Алешина Л.В., кандидат химических наук, доцент кафедры физики и химии Уральского государственного экономического университета. 
UDC 631.41:631.453

\title{
ACCUMULATION OF HEAVY METALS IN THE SOILS OF THE SVERDLOVSK REGION
}

\author{
Galina V. Kharina1, \\ gvkharina32@yandex.ru \\ Ludmila V. Aleshina², \\ alv@usue.ru \\ 1 Russian State Vocational Pedagogical University, \\ 11, Mashinostroiteley street, Ekaterinburg, 620012, Russia. \\ 2 Ural State University of Economics, \\ 62, Vosmoe Marta street, Ekaterinburg, 620144, Russia.
}

The relevance of the study is dictated by the need for constant environmental monitoring of environmental objects in the Sverdlovsk region, in particular soils, due to the high level of anthropogenic load on the territory.

The purpose of the work is to assess the degree of contamination of residential landscapes and agricultural lands in the Sverdlovsk region with heavy metals by determining the concentration of gross forms of heavy metals and calculating quantitative criteria for contamination with heavy metals

Objects: soil samples from several points of the Sverdlovsk region, representing urbanized territories and agricultural land.

Methods: mechanical and chemical sample preparation of soils; potentiometric method for determining the nature of the soil environment; inversion voltammetry method for determining the concentration of gross forms of heavy metals.

Results. The correspondence of sampling points to soil provinces is established, a brief description of the granulometric and geochemical composition of the studied soils is given. It was found that the analyzed soils are contaminated with nickel, zinc, lead and copper; there is a multiple excess of the approximate permissible concentrations of nickel in the soils of Ekaterinburg and Pervouralsk. The main sources of technogenic soil pollution of the Sverdlovsk region with heavy metals are listed. Natural factors contributing to the accumulation of metals are considered; possible mechanisms of fixing heavy metals in the soils of the region are described. The ranking of metal pollutants by their content in the studied soils was carried out. Quantitative criteria for the degree of soil pollution are calculated: the total pollution index and the geoaccumulation index. Based on the obtained values of the specified parameters, it is shown that the soils of residential landscapes are characterized by a moderately dangerous level of pollution, agricultural soils - an acceptable level of pollution. It was found that the greatest contribution to the total pollution index is made by cadmium.

\section{Key words:}

Heavy metals, technogenic pollution, residential landscape, accumulation, geochemical composition.

\section{REFERENCES}

1. Sostoyanie i perspektivy ispolzovaniya mineralno-syryevoy bazy Sverdlovskoy oblasti na 15.03.2021. Spravka podgotovlena FGPU «VSEGEI» v ramkakh vypolneniya Gosudarstvennogo zadaniya federalnogo agenstva po nedropolzovaniyu ot 4.01.2021 № 04900016-21-00 [The state and prospects for the use of the mineral resource base of the Sverdlovsk region as of 03.15.2021. The reference was prepared by FSBI VSEGEI as part of the State Assignment of the Federal Agency for Subsoil Use dated January 14, 2021, No. 049-00016-21-00]. Available at: https://rosnedra. gov.ru/data/Fast/Files/202104/8cb09d4c5ef96b69de56b70811dd1d 5a.pdf (accessed 30 July 2021).

2. Kasimov N.S., Vlasov D.V. Heavy metals and metalloids in the soils of Russian cities (according to the annual reports of Roshydromet). Vestnik Moskovskogo universiteta. Seriya 5. Geografiya, 2018, no. 3, pp. 14-22. In Rus.

3. Kharina G.V., Aleshina L.V., Anakhov S.V., Inzhevatova O.V. Monitoring of drinking water quality in the Sverdlovsk region of Russia. Water and ecology: problems and solutions, 2020, no. 1 (83), pp. 63-83. In Rus.

4. Mng'ong'o M., Comber S., Munishi L.K., Ndakidemi P.A., Blake W., Hutchinson T.H. Potentially toxic elements status and distribution in Usangu agroecosystem-Tanzania. Environmental Challenges, 2021. Available at: https://doi.org/10.1016/j.envc. 2021.100200 (accessed 30 July 2021).

5. Mikheeva E.V., Baitimirova E.A., Goldypeva E.V. Chemical safety of the population: natural component. Civil Security Technologies, 2009, vol. 6, no. 3-4, pp. 137-143. In Rus.

6. Li Z., Ma Z., van der Kuijp T.J., Yuan Z., Huang L. A review of soil heavy metal pollution from mines in China: pollution and health risk assessment. Science of the Total Environment, 2014, vol. $468-469$, pp. 843-853.
7. GOST 17.4.3.01-83. Okhrana prirody. Pochvy. Obshchie trebovaniya $k$ otboru pochv [State Standard 17.4.3.01-83. Protection of Nature. Soils. General requirements for the selection of soils]. Moscow, StandardInform Publ., 2008. 4 p. Available at: https://docs.cntd.ru/document/1200012800 (accessed 30 July 2021).

8. Braynina Kh.Z., Neyman E.Ya. Tverdofaznye reaktsii $v$ elektroanaliticheskoy khimii [Solid-phase reactions in electroanalytical chemistry]. Mosocw, Khimiya Publ., 1982. 264 p.

9. Gafurov F.G. Pochvy Sverdlovskoy oblasti [Soils of the Sverdlovsk region]. Yekaterinburg, Ural University Publ. house, 2008. $396 \mathrm{p}$.

10. Orientirovochno dopustimye kontsentratsii (ODK) tyazheykh metallov $i$ myshyaka v pochvakh: GN 2.1.7.020-94 (Dopolnenie № $1 \mathrm{k}$ perechnyu PDK i ODK № 6229-91) [GN 2.1.7.020-94. Approximately permissible concentrations (OEC) of heavy metals and arsenic in soils: GN 2.1.7.020-94 (Supplement no. 1 to the list of MPC and OEC no. 6229-91]. Approved. GKSN RF. 12.27.94. Moscow, $1995.7 \mathrm{p}$.

11. GOST 17.4.1.02-83. Okhrana prirody. Pochvy. Klassifikatsiya khimicheskikh veshchestv dlya kontrolya zagryazneniya [State Standard 17.4.1.02-83. Protection of Nature. Soils. Classification of chemicals for pollution control]. Moscow, Gosstandart Publ.,1983. 3 p.

12. Pacyna E.G., Pacyna J.M., Fudala J. Current and future emissions of selected heavy metals to the atmosphere from anthropogenic sources in Europe. Atmospheric Environment, 2007, vol. 41, no. 38 , pp. $8557-8566$.

13. Shabanov M.V., Marichev M.S. Heavy metals in the soils of geochemically conjugated landscapes of the Krasnouralsk industrial hub. Socio-ecological technologies, 2020, vol. 10, no. 2, pp. 201-225. In Rus. 
14. Ferreira P.A.A., Lourenzi C., Tiecher T., Tiecher T.L., Ricachenevsky F., Brunetto G., Giachini A.J., Sauso Suares C.R.F. Physiological, biochemical changes, and phytotoxicity remediation in agricultural plant species cultivated in soils contaminated with copper and zinc. Plants under Metal and Metalloid Stress. Eds. M. Hasanuzzaman, K. Nahar, M. Fujita. Singapore, Springer, 2018 pp. 29-76. Available at: https://doi.org/10.1007/978-981-13-2242-62 (accessed 30 July 2021).

15. Baitimirova E.A., Mikheeva E.V., Bespamyatnykh E.N., Donnik I.M. Krivonogova A.S. Assessment of pollution of recreational zones of a megapolis with heavy metals (on the example of Yekaterinburg). Agrarian Bulletin of the Urals, 2016, no. 4, pp. 71-77. In Rus.

16. Heike B.B. Adsorption of heavy metal ions on soils and soils constituents. Journal of Colloid and Interface Science, 2004, vol. 277, Iss. 1, pp. 1-18.

17. Vasiliev A.A., Chashchin N.N. Chashchin N.N. Tyazhelye metally $v$ pochvakh goroda Chusovogo: otsenka i diagnostika zagryazneniya. Monografiva [Heavy metals in the soils of the city of Chusovoy: assessment and diagnostics of pollution. Monograph]. Perm, FGBOU VPO Perm State Agricultural Academy Publ., 2011. $197 \mathrm{p}$.

18. Brian J.A. Sources of heavy metals and metalloids in soils. Heavy Metals in Soils, 2012, vol. 22, pp 11-50.

19. Ilyin V.B. Tyazhelye metally $v$ sisteme pochva-rastenie [Heavy metals in the soil-plant system]. Novosibirsk, Nauka Publ., Sib. Department, 1991. $151 \mathrm{p}$.

20. Ford R.G., Scheinost A.C., Scheckel K.G., Sparks D.L. The link between clay mineral weathering and the stabilization of $\mathrm{Ni}$ surface precipitates. Environmental Science Technology, 1999, vol. 33, pp. 3140-3144.

21. Lukin S.V. Monitoring soderzhaniya nikelya $\mathrm{v}$ pochvakh [Monitoring of nickel content in soils]. Achievements of science and technology of the agro-industrial complex, 2011, no. 3, pp. 14-16.

22. Martinez C.E., Bazilevskaya K.A., Lanzirotti A. Zinc coordination to multiple ligand atoms in organic-rich surface soils Environmental Science Technology, 2006, vol. 40, pp. 5688-5695.

23. Cismasu A.C., Ona-Nguema G., Bonnin D., Menguy N., Brown G. Zinc and arsenic immobilization and magnetite formation upon maghemite reduction by shewanella putrefaciens ATCC 8071 . Geochimica et Cosmochimica Acta, 2008, vol. 72 (12), p. A165.

24. Cooper D.C., Picardal F., Rivera J., Talbot C. Zinc immobilization and magnetite formation via ferric oxide reduction by Shewanella putrefaciens. Environmental Science Technology, 2000, vol. 34, pp. 100-106.

Information about the authors

Galina V. Kharina, Cand. Sc., associate professor, Russian State Vocational Pedagogical University.

Ludmila V. Aleshina, Cand. Sc., associate professor, Ural State University of Economics.
25. Ford R.G., Sparks D.L. The nature of $\mathrm{Zn}$ precipitates formed in the presence of pirophyllite. Environmental Science Technology, 2000, vol. 34. pp. 2479-2483.

26. McBride M.B., Sauve S., Hendershot W. Solubility control Cu, Zn, $\mathrm{Cd}$ and $\mathrm{Pb}$ in contaminated soils. European Journal Soil Science, 1997, vol. 48, pp. 337-346.

27. Xia K., Bleam W., Helmke P.A. Studies of the nature of $\mathrm{Cu}^{2+}$ and $\mathrm{Pb}^{2+}$ binding sites in soil humic substances using $\mathrm{x}$-ray absorption spectroscopy. Geochimica Cosmochimica Acta, 1997a, vol. 61, pp. 2211-2221.

28. Kubier A., Wilkin R.T., Pichler T. Cadmium in soils and groundwater: a review. Applied Geochemistry, 2019, vol. 108, P. 104388.

29. Krishnamurti G.S.R., Naidu R. Solid-solution equilibria of cadmium in soils. Geoderma, 2003, vol. 113 (1-2), pp. 17-30.

30. Obzor fonovogo sostoyaniya okruzhayushchey prirodnoy sredy na territorii stran SNG za 2008 god [Review of the background state of the natural environment in the territory of the CIS countries for 2008]. Ed. by Yu.A. Izrael. Roshydromet, 2010. 103 p. Available at: http://downloads.igce.ru/publications/reviews/fon2008.pdf (accessed 30 July 2021)

31. MU 2.1.7.730-99. Gigienicheskaya otsenka kachestva pochvy naselennykh mest. Metodicheskie ukazaniva [MU 2.1.7.730-99. Hygienic assessment of soil quality in populated areas. Methodical instructions]. Moscow, Federal Center for State Sanitary and Epidemiological Supervision of the Ministry of Health of Russia Publ., 1999. 38 p.

32. Vodyanitskiy Yu.N. Tyazhelve metally $i$ metalloidv $v$ pochvakh [Heavy metals and metalloids in soils]. Moscow, V.V. Dokuchaeva GNU Soil Institute RAAS Publ., 2008. 84 p.

33. Zagryaznenie pochv Rossiyskoy Federatsii toksikantami promyshlennogo proiskhozhdeniya $v 2019$ godu [Soil pollution of the Russian Federation with industrial toxicants in 2019. Yearbook]. Obninsk, FSBI NPO Typhoon Publ., 2020. 129 p.

34. Shabanov M.V., Strekulev G.B. Geochemical processes of accumulation of heavy metals in the landscapes of the South Urals. Bulletin of the Tomsk Polytechnic University. Geo Assets Engineering, 2021, vol. 332, no. 1, pp. 184-192. In Rus.

35. Charzyński P., Plak A., Hanaka A. Influence of the soil sealing on the geoaccumulation index of heavy metals and various pollution factors. Environmental Science and Pollution Research, 2017, vol. 24, pp. 4801-4811.

Received: 9 February 2022. 